\title{
RECUPERACIÓN DEL MUNDO PRECOLOMBINO Y COLONIAL EN LA NARRATIVA DE MIGUEL ÁNGEL ASTURIAS
}

\author{
GIUSEPPE BELLINI
}

Cfr. Giuseppe Bellini, La narrativa di Miguel Angel Asturias, Milano, Cisalpino, 1966.

\section{2}

Marc Cheymol, Miguel Ángel Asturias dans le Paris des Années Folles, Grenoble, Université de Grenoble, 1987.

3

Luis López Álvarez, Conversaciones con Miguel Ángel Asturias, Madrid, Editorial Magisterio Español, 1974, pág. 75.

4

Claude Couffon, Miguel Ángel Asturias, Paris, Seghers, 1970, pág. 19.
Recuperación del mundo precolombino y colonial en la narrativa de Miguel Ángel Asturias GIUSEPPE BELLINI
1. Toda la obra creativa de Miguel Ángel Asturias se desarrolla dentro de una recuperación activa del mundo precolombino y de la Colonia. Del primero el escritor guatemalteco interpreta el sentido profundo; del segundo la sugestión de un pasado no solamente llamativo y fabuloso, sino contradictorio y conflictivo que permanece actual si no en la realidad plena de Guatemala, en la sensibilidad del escritor, y nunca percibido como retraso frente a la modernidad.

Como ya puse de relieve hace años ${ }^{1}$, el momento en el cual Asturias descubre el valor y el significado de pertenecer a un mundo de civilización no inferior al de las grandes civilizaciones occidentales, está representado por los años Veinte, durante los cuales, olvidado su propósito de especializarse en derecho en Inglaterra, se establece en París, adonde llega el 12 de julio de 1924, y empieza a seguir en el «Collège de France» las clases del doctor Capitan sobre Antigüedades mexicanas y las del profesor Georges Raynaud, en la «École des Hautes Etudes», sobre Religiones de Mesoamérica.

Serán también los famosos «Années folles» de los que habla $\mathrm{Marc}^{\mathrm{Ch}} \mathrm{Cmol}^{2}$, los de las grandes experiencias artísticas de la Vanguardia, la tímida frecuentación de los grandes renovadores de las letras y las artes, incluso maestros españoles como Unamuno, Valle-Inclán y Baroja; son sobre todo los años del descubrimiento de sus raíces culturales maya, con la superación del complejo de inferioridad propio del latinoamericano que por entonces entraba en contacto con el mundo deslumbrante de la Ville Lumière, capital mundial de la cultura.

Efectúa el milagro el profesor Raynaud con sus cursos y la atención que le dedica al joven guatemalteco, en quien ve concretizarse las facciones de los maya. Lo recuerda el escritor en sus conversaciones con Luis López Álvarez ${ }^{3}$. Lejos de sucumbir a la nota del folclore, Asturias aprecia la atención y empieza a ahondar en una dimensión antes inadvertida de sí mismo, ayudado por el descubrimiento de textos fundamentales del mundo indígena, que el citado profesor Raynaud le induce a traducir de su versión francesa al castellano: el Popol-Vub y los Anales de los Xabil. Asturias realiza las traducciones de ambas obras con el mexicano J. M. González de Mendoza y las publica en París: el Popol-Vuh en 1927, con un título sugestivo, Los Dioses, los Héroes y los Hombres de Guatemala antigua, y al año siguiente los Anales. Tiempo después confesará a Claude Couffon que

Ce fut une expérience épuisante mais très utile. L'exigence de Raynaud pour l'exactitude du vocabulaire et la fidélité à l'interprétation magique nous obligeait à passer du mot français au mot quiché et à chercher inlassablement des synonymes en espagnol. ${ }^{4}$. 
El rigor en la interpretación de los textos del pasado maya, no fue más que el trámite necesario para alcanzar el mensaje profundo, penetrar y dejarse penetrar por ese clima mágico, que determinaría luego toda la orientación de Miguel Ángel Asturias, ya con ambiciones de escritor, pero hasta entonces explicablemente inseguro acerca de los derroteros de su vida; derroteros que se le aclararían más tarde y cuyo primer fruto sería algo en cierta manera «mestizo». En efecto, la valorización de lo precolombino se mezclaría con la sugestión ejercitada sobre el joven escritor por una fantástica y complicada permanencia en su país de una atmósfera colonial y todo cuajaría en las Leyendas de Guatemala, que publica en 1930 en la madrileña Editorial Oriente.

Un primer paso, pero se necesitaría más tiempo todavía para que Asturias diera con su verdadero camino, y eso empezó a aclararse a partir de El Señor Presidente, novela terminada ya en 1932 y publicada sólo en 1946, texto donde el halo de la Colonia y la sugestión del mito se unen con la protesta política. A la misma época pertenece El Alhajadito, que, ulteriormente elaborado, el escritor publica en 1961, y comienza la elaboración de su gran novela, Hombres de maíz, que aparecerá en 1949 , inicio de una verdadera y por mucho tiempo inadvertida revolución, por estructura y estilo, dentro de la tradicional narrativa hispanoamericana, antes de que la crítica empiece a hablar de «nueva novela».

Durante el período parisino el joven Asturias desarrolla una intensa actividad también como periodista ${ }^{5}$, no deja de escribir cuentos y tampoco poemas y teatro. Los temas de las Leyendas, como amplios capítulos de El Señor Presidente, son objeto primero de narración oral a sus compañeros, entre los cuales se contaban futuros escritores eminentes: Alfonso Reyes, Arturo Uslar Pietri, Alejo Carpentier entre ellos. De todo deja Asturias repetida constancia en sus entrevistas y hasta en una breve (Auto)biografía que me favoreció en $1963^{6}$, cuando yo estaba preparando un libro sobre su obra narrativa?.

2. En las Leyendas de Guatemala, que impresionaron positivamente, en la traducción francesa de Francis de Miomandre, al poeta Paul Valéry -desde la segunda edición castellana el libro llevaría como prólogo la carta de éste al traductor-, Asturias se hace intérprete del mundo guatemalteco cual se le presenta, caracterizado por lo indígena y el halo de la Colonia. La realidad dentro de la cual Asturias había vivido, entre la capital de Guatemala y la provincia, Salamá, adonde sus padres habían tenido que refugiarse para huir de la persecución del tirano Estrada Cabrera, lo había puesto en íntimo contacto con una atmósfera donde el mestizaje de elementos constituía la actualidad, y lo había absorbido profundamente. Se explican así leyendas como la del Cadejo, de la Tatuana o del Sombrerón, atmósferas libradas entre santos y diablos, frailes y monjas, arrebatos místicos y tentaciones demoníacas, que evocan una época de conventos, personajes encopetados, misteriosas estancias, zaguanes donde el Maligno asoma por todas partes.

También es individuable un influjo literario múltiple: de las «tradiciones» de Ricardo Palma, de la formación modernista del escritor, admirador del poeta Santos Chocano, sus lecturas del Valle-Inclán del «esperpento», en particular de la novela Tirano Banderas, determinante, como bien sabemos, en la elaboración de El Señor Presidente.

En las narraciones de Asturias se mezclan los climas de una Colonia supersticiosa y de rancia nobleza, atractiva y mágica, la dimensión profunda, misteriosa y sugerente de lo indígena, que se manifiesta en la creación del artista con colores novedosos, inédita poesía, a través de un lenguaje rico en neologismos y onomatopeyas, representando un mundo, región del espíritu, materializado en una actualidad dominada por un aire remoto, que asoma por debajo de las estructuras con las que la Colonia parecía haberlo condenado al silencio.

Todo parece formarse, se diría, en una atmósfera de lentitud meditativa, que poco a poco otorga consistencia a caserones, calles y plazas, a dimensiones secretas, que asoman desde los estratos superpuestos de antiguas ciudades y a través de las cuales, como en la estampa titulada Guatemala, se alcanza, en una suerte de sueño en la niebla, «el tiempo viejo de las horas viejas».

Las ciudades sagradas del mundo precolombino lo dominan todo con su sugestión;
5 Cfr. Miguel Ángel Asturias, Paris 1924-1933. Peridodismo y creación literaria, ed. crítica, Amos Segala coordinador, Madrid, ALLCA, "Colección Archivos», $1996,2^{2}$. ed

6

G. Bellini, Mundo mágico y mundo real. La narrativa de Miguel Ángel Asturias, Roma, C.N.R.Bulzoni Editore, 1999.

7

Cfr. G. Bellini, La narrativa di Miguel Ángel Asturias, op. cit. 


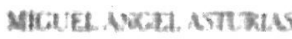 \\ Leyendas de Guatemala}

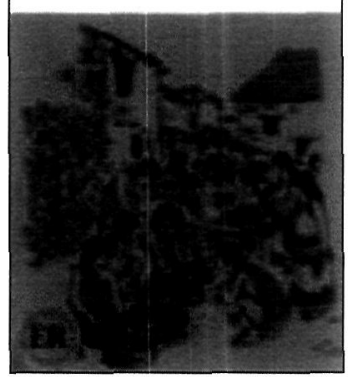

8

M. A. Asturias, "Guatemala», en Leyendas de Guatemala, ed. de Alejandro Lanoël, Madrid, Cátedra, 1995, pág. 89.

9

Ibidem, pág. 90.

10

Ibidem.

11

lbidem, pág. 91.

12

Ver «Leyenda del Cadejo», ibidem.

13

«Leyenda del Sombrerón», ibidem.

14

«Guatemala», ibidem, pág. 91

15

Ibidem, pág. 85

16

«Los brujos de la tormenta primaveral», ibidem, pág. 129.
Recuperación del mundo precolombino y colonial en la narrativa de Miguel Ángel Asturias GIUSEPPE BELLINI resucitan a la vida los sacerdotes, el rey, los hombres «pintados de rojo, cuya nariz adorna un raro arete de obsidiana», las doncellas "teñidas con agua de barro sin quemar, que simboliza la virtud de la gracia», los sacrificios... $^{8}$ en un trasfondo colonial, evocado en los «azulejos de Génova», las «colgaduras de Damasco», los «tafetanes de Granada», hasta en los obispos que se pudrieron por malos pensamientos, "las candelas sin llamas y la Virgen sin ojos en la sombra» ${ }^{9}$, religiosos y religiosas: Fray Payo Enríquez de Rivera, que «lleva oculta en su sotana la luz», la primera imprenta; el «hermano» Pedro de Betancourt, un santo, de paso imperceptible: "Anda como vuela una paloma»10; los amantes felices; el «hermano Pedro» dormido en la capilla y por ende «más cerca que nunca de los brazos de Nuestra Señora»11.

A estos personajes se añaden en las leyendas sucesivas la madre Elvira de San Francis$\mathrm{co}$, insidiada por el Cadejo y victoriosa sobre él' ${ }^{12}$, el monje hechizado por la pelota de hule, nada menos que «el Sombrerón», el diablo, del que logra liberarse ${ }^{13}$.

Asturias evoca de esta manera, en las Leyendas, su mundo y desde París lo proyecta casi como un reto en la modernidad más culta, como sustancia insuprimible del país y de su propia espiritualidad:

-¡Mi pueblo! ¡Mi pueblo, repito, para creer que estoy llegando! Su llanura feliz. La cabellera espesa de sus selvas. Sus montañas inacabables que al redor de la ciudad forman la Rosca de San Blas. Sus lagos. La boca y la espalda de sus cuarenta volcanes. El patrón Santiago. Mi casa y las casas. La plaza y la iglesia. El puente. Los ranchos escondidos en las encrucijadas de las calles arenosas. Las calles enredadas entre los cercos de yerba-mala y chichicaste. El río que arrastra continuamente la pena de los sauces. Las flores de izote. ¡Mi pueblo! ¡Mi pueblo!!4

Esbozo fascinante de la capital guatemalteca a través de simples notaciones, inventario encerrado entre dos series de exclamaciones que denuncian transporte sentimental; mundo que se ampliará en otras, repetidas ocasiones, a todo Guatemala, ese "País verde. País de los árboles verdes», que el narrador y poeta exaltará con nostalgia en El espejo de Lida Sal, y al que dedicará páginas inolvidables en todas sus novelas, a partir de Hombres de maíz, para acabar con Viernes de dolores.
Todo dentro de un tiempo lento, en el cual parece abrirse el telón de fondo de las revelaciones; tiempo que el comienzo de las Leyendas inaugura, sencillo y sagrado, lleno de misterio:

La carreta llega al pueblo rodando un paso hoy y otro mañana. En el apeadero, donde se encuentran la calle y el camino, está la primera tienda. Sus dueños están viejos, tienen güegüecho, han visto espantos, andarines y aparecidos, cuentan milagros y cierran la puerta cuando pasan los húngaros: esos que roban niños, comen caballo, hablan con el diablo y huyen de Dios ${ }^{15}$.

Sabiduría y experiencia, en cierta manera prefiguración de personajes futuros: Celestino Yumí y su esposa, cuando ya viejos regresan a Quiavicús, en Mulata de Tal.

En las Leyendas de Guatemala se abren paso igualmente interpretaciones profundas de lo precolombino, meditadas y adherentes al espíritu del Popol-Vuh, como en la Leyen$d a$ del tesoro del lugar florido, o en la de Los Brujos de la tormenta primaveral, sobre todo, donde el autor recrea originalmente el momento inaugural del mundo.

En la antigua «Biblia de los quichés» todo se realiza dentro de un majestuoso silencio: el de la materia en potencia, que los dioses creadores y formadores disponen mano a mano que «sea»; en Los brujos de la tormenta primaveral, al contrario, todo es sonido y color, procede como de una catástrofe, protagonistas los volcanes. Preside la experiencia personal de Asturias en un país de temblores, donde incansablemente desde la muerte se repite el milagro de la vida. Si «más allá de los peces» el mar se había quedado solo, si «las raíces habían asistido al entierro de los cometas en la planicie inmensa de lo que ya no tiene sangre, y estaban fatigadas y sin sueño», si se había acortado el ritmo de la respiración vegetal y enfriado «la savia al entrar en contacto con la sangre helada de los asaltantes elásticos», todo volvería pronto a vivir: pajaros, peces, raíces, insectos...16.

La creación del mundo la representa Asturias como lo que es: un acontecimiento sagrado, un espectáculo majestuoso de la materia que, de temblor en temblor, de destrucción en destrucción, va cobrando forma:

Los ríos navegables, los hijos de las lluvias, los del comercio carnal con el mar, andaban en la superficie de 
la tierra y dentro de la tierra en lucha con las montañas, los volcanes y los llanos engañadores que se paseaban por el suelo comido de abismos, como balsas móviles. Encuentros estelares en el tacto del barro, en el fondo del cielo, que fijaba la mirada cegatona de los crisopacios, en el sosegado desorden de las aguas errantes sobre lechos invisibles de arenas esponjosas, y en el berrinche de los pedernales enfurecidos por el rayo $0^{17}$.

De sacudida cósmica en sacudida, de catástrofe en catástrofe es como surge la vida, vegetal y mineral, hasta que por fin aparecen el animal y el hombre.

Los brujos de la tormenta primaveral no constaba en la primera edición de Leyendas de Guatemala; aparece por primera vez en la bonaerense de $1948^{18}$, y es fruto de una nueva meditación acerca del Popol-Vub, cuando ya Asturias con la publicación de El Señor Presidente había regresado del largo silencio en que parecía haberse hundido tras su primer libro. Silencio creativo, sin duda, que le había permitido profundizar en sus raíces culturales.

3. En la novela dedicada a la protesta contra la dictadura, El Señor Presidente, tampoco fal$\tan$ influjos de lo precolombino. No es superficial, en el capítulo XXXVII, el acercamiento del tirano a Tohil, que en el Popol-Vuh aparece como primer dios de los hombres de maíz, dador del fuego y del agua, a cambio de sacrificios humanos. Parecido a él el Presidente: que otorga y retira su gracia a cambio de crímenes. Su ex favorito, Cara de Ángel, es un títere en sus manos y finalmente morirá en la cárcel por haberse negado al delito. La visión premonitoria que se le ofrece al personaje, en el momento de despedirse del dictador, repite el ritual mítico, identificando, al signo del chantaje y la crueldad, al Señor Presidente con el dios antiguo:

«!Estoy contento!», dijo Tohil. ¡Re-tún-tún! ¡Retún-tún!, retumbó bajo la tierra. «iEstoy contento! Sobre hombres cazadores de hombres puedo asentar mi gobierno. No habrá ni verdadera muerte ni verdadera vida. ¡Que se me baile la jícara!»

Y cada cazador guerrero tomó una jícara, sin despegársela del aliento que le repellaba la cara, al compás del tún, del retumbo y el tún de los tumbos y el tún de las tumbas, que le bailaban los ojos a Tohil.

Cara de Ángel se despidió del Presidente después de aquella visión inexplicable. [...] ${ }^{19}$.
Conclusión fúnebre, evocada mágicamente por la onomatopeya insistida del tun, que acaba en tumba.

4. En la sucesiva novela, Hombres de maíz, la fusión de lo precolombino y lo colonial se realiza interpretando una realidad mestiza, cuyo fundamento reside en la magia. Asturias ha absorbido con plena conciencia la mentalidad indígena y en esta novela da vida a un particular realismo, el conocido «realismo mágico", anunciado ya en las Leyendas y El Albajadito, pero dominante aquí, en la representación de una realidad que corresponde a la visión indígena y se expresa en «un relato que va en dos planos: un plano de la realidad y un plano de lo irreal». El indígena, en efecto, explicará en época más tarda Asturias,

cuando habla de lo irreal, da tal cantidad de detalles de su sueño, de su alucinación, que todos esos detalles convergen para hacer más real el sueño y la alucinanción que la realidad misma. Es decir que no puede hablarse de este realismo mágico sin pensar en la mentalidad primitiva del indio, en su manera de apreciar las cosas de la naturaleza y en sus profundas creencias ancestrales ${ }^{20}$.

El secreto consiste en la adhesión a esas «creencias ancestrales» desde la conciencia de que son «creencias», e interpretan, a pesar de ello, la esencia de un pueblo. Por eso, entrado en el clima, nada maravilla al lector en Hombres de maíz: ni que el Gaspar Ilóm oiga la voz de la tierra, o que el señor Nicho Aquino se transforme en su nábual, el coyote, ni que María Tecún sea al mismo tiempo un ser humano y una montaña, ni las demás mirabilia.

También en el estilo Asturias revela la lección que dejó en él el Popol-Vuh, de la que hace uso deliberadamente, así como en la novela, de la presentación de Gaspar Ilóm escuchando en el sueño mito del «hombre de maíz». Es suficiente ver, al comienzo, el inquieto mensaje de las potencias misteriosas de la tierra, preocupadas por las destrucción de los bosques, realizadas por los maiceros. Para suscitar una atmósfera mágica, Asturias acude, como en el texto quiché, a la iteración y al paralelismo, dando de esta manera dimensión profunda a lo oculto.

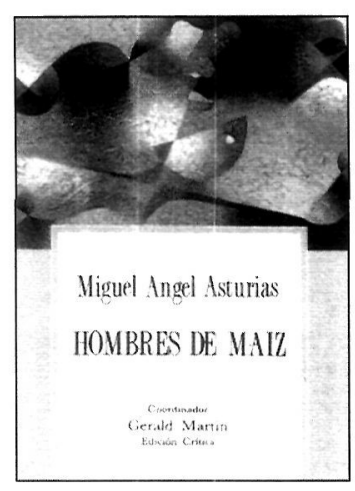

17

Ibidem, pág. 113.

18

M.A. Asturias, Leyendas de Guatemala, Buenos Aires, Editorial Losada, 1948.

19

M. A. Asturias, El Señor Presidente, ed. de Selena Millares, Madrid, Anaya \& Mario Muchnik, 1995, pág. 302.

20

Cfr. M. A. Asturias en L. López Álvarez, op. cit., pág. 166.

Recuperación del mundo precolombino y colonial en la narrativa de Miguel Ángel Asturias

GIUSEPPE BELLINI 
21

Lucía Chen (Hsiao-Chuan Chen), La dictadura y la explotación: un estudio de la trilogía bananera de Miguel Ángel Asturias, México, Cuadernos Americanos, UNAM, 2000.

22

M. A. Asturias, Los ojos de los enterrados, Buenos Aires, Editorial Losada, 1961, págs. 232233.

23

Jean-Michel Barascud, "La creación mítica en la Trilogía bananera de Miguel Ángel Asturias: Quetzalcoatl versus Superman», en Actas del Coloquio internacional 1899-1999. Un siècle / Un siglo de Miguel Ángel Asturias, Poitiers, CRLA-Archivos, 2001, pág. 111.

24

Ibidem, pág. 121.

25

Cfr. mi lejano libro La narrativa di Miguel Ángel Asturias, cit., y nuevamente en Mundo mágico y mundo real. La narrativa de Miguel Ángel Asturias, Roma, C.N.R.-Bulzoni Editore, 1999.

\section{6}

Jean-Philippe Barnabé, "La escritura de la leyenda asturiana: fragmentos de un historial», en M. A. Asturias, Cuentos y leyendas, edición crítica de Mario Roberto Morales, Madrid, ALLCA XX, «Colección Archivos», 2000, pág. 490.

Recuperación del mundo precolombino y colonial en la narrativa de Miguel Ángel Asturias GIUSEPPE BELLINI
5. Tampoco faltan elementos de raíz mítica indígena en la «Trilogía bananera», como ha puesto agudamente de relieve Lucía Chen ${ }^{21}$. El título de la novela Viento fuerte anuncia al huracán justiciero que destruirá la Compañía norteamericana del banano, y el de Los ojos de los enterrados alude a la paz que solamente encontrarán los muertos cuando se restablezca la libertad en el país:

¡Ah, ese día, el día de la verdadera victoria sobre la compañía bananera, bajo la tierra se oirá como un retumbo al caer los párpados sobre las pupilas desnudas y fijas de los enterrados que están esperando con los ojos abiertos! ${ }^{22}$

El problema socio-político domina en estas novelas comprometidas, como domina el problema político nacional en Week-end en Guatemala. La trilogía, y en máxima parte Week-end, representan una suerte de paréntesis dentro de la línea de interpretación-interiorización propia de las Leyendas. Sin embargo, con razón Jean-Michel Barascud señala en toda la obra de Asturias su coherencia, que parte de la «certeza» de que «Existió en la tierra un mundo ideal, pero, a consecuencia de una especie de pecado original, el ser humano quedó excluido y desde entonces busca en vano el camino de regreso» ${ }^{23}$. Es ésta, la visión dominante que proyecta el Popol-Vuh, y sobre ella el escritor guatemalteco funda su teoría de «restauración». Su certeza, o mejor su obstinada esperanza, es que no podrá dejar de llegar el momento del rescate, y será obra de hombres nuevos redentores, como Octavio Sansur, vuelto Tabio San, en la última novela de la trilogía. Nuevo Quetzalcoatl, este personaje revive de las cenizas para rescatar a sus semejantes; identificación que al citado Barascud le parece clara, sea por la «semejanza biográfica como por las alusiones físicas y el vocabulario empleado»; el crítico observa que «los dos comparten la misma preocupación pacifista, el mismo papel redentor y de taumaturgo, el simbolismo de la victoria de la vida sobre la muerte: el mito ha propuesto, pues, una solución de esperanza para el presente $»^{24}$. $\mathrm{O}$, como en su tiempo yo interpretaba: por encima del desaliento del presente que domina en Viento fuerte, El Papa Verde y Week-end en Guatemala, Los ojos de los enterrados constituye una obstinada vuelta a la esperanza, utópica como la de Neruda, debido a la época, pero conforme con la misión plenamente asumida por el escritor hacia su pueblo ${ }^{25}$.

6. Al clima mítico regresa definitivamente Asturias a partir de El Albajadito, que publica en 1961, revisado, vuelto a elaborar, con toda una serie de añadiduras. Llega a su punto más alto en Mulata de tal y continúa con $M a-$ ladrón, cuyo subtítulo Elegía de los Andes Verdes introduce al lector en un conflicto que no consiste solamente en el choque material entre indígenas y europeos, sino en el encuentro-choque entre dos concepciones del mundo, donde materialmente la indígena queda vencida, aunque, como ocurrió con Grecia y Roma, estaba destinada a sobrevivir y a actuar en profundidad en la cultura mestiza a la que daban comienzo los vencedores. Para Asturias el mestizaje representa la síntesis final positiva del encuentro violento. No inútilmente, aludiendo al nacimiento del primer fruto de india y español, recorre el libro un leitmotiv nimbado de sacralidad: «Todo está ya lleno de comienzos».

Desde hacía tiempo Asturias vivía en el exilio, y de nuevo se le hacía presente, más que nunca, el mundo hacia el cual iba su añoranza. En El Alhajadito el motivo político es dejado a un lado, aunque en realidad persiste subyacente. La magia del sueño, el mito, la leyenda, las tradiciones populares dominan en el texto, en cuanto medio para hacer concreto el inapresable mundo espiritual de Guatemala.

Jean-Philippe Barnabé ha declarado, fundándose en la documentación «Archivos» de la Bibliothèque National de Paris, que, posiblemente, el sector fundamental de El Albajadito es la parte final eliminada de la novela Maladrón ${ }^{26}$. En efecto, el libro se presenta extrañamente estructurado: a la primera parte, que se desarrolla en un clima que podría conectarse con la citada novela, sigue una serie de cuentos poéticos compuestos por el escritor para su hijo pequeño, Miguel Ángel. Durante una lejana conversación en Milán, Asturias me declaró que El Alhajadito remontaba en su primera versión a la época parisina, los años 1925-1928; recién nombrado embajador en El Salvador, su esposa había encontrado casualmente el manuscrito en su casa de Guatemala; sorprendido por el hallazgo, él había vuelto a elaborar esas páginas, que publicaría años después, aña- 
diendo, prosificados, los «cuentos del cuy», apodo que le daba a su hijito, cuentos que, como confirma Jimena Sáenz, le había seguido enviando de enero a marzo de 1947 a México, donde el niño residía ${ }^{27}$.

La elaboración del material encontrado debió de ser radical, y ciertamente incluyó páginas nuevas de extraordinaria invención, como las del triunfo circense, el «Nadir custodio» y el abracadabrante comedor de fuego, que se incendia y muere, provocando el frenético entusiasmo del inocente Alhajadito. Realidad y magia se mezclan en estos acontecimientos acentuando el clima misterioso que rodea la casona de los Alhajados. Anima el texto una dimensión profunda: la adhesión a la sensibilidad con que, como enseña el Popol$V u h$, el indígena percibe el mundo, maravilla de la creación en sus más mínimos componentes. Lo que le pasa al pequeño de los Alhajados, ante el milagro de vidas que se le revela de repente con sólo dar con un pie en el suelo: «¡Cuántos ojos, no sólo ojos... gotitas de agua viva, luminosas gotitas de agua inteligente! ¡Cuántos movimientos en la oscuri$\mathrm{dad} !{ }^{28}$. Con estas páginas el escritor vuelve a adentrarse en un ámbito que le es propio y que mueve poderosamente su imaginación.

\section{Producto relevante del nuevo momento} creativo asturiano es la novela de «la Mulata», como el propio autor la mencionaba: Mulata de tal, que publica en 1963.

Se puede afirmar que en este libro Asturias celebra sus esponsales con el mundo indomestizo, dando uno de los textos más complicados y más altos de su creación: himno y elegía a un mundo de permanente significado, paraíso fijo en el tiempo, mundo fortalecedor frente a la desilusión de lo real.

Es en Mulata de tal donde más se aprecia la importancia que para Asturias tiene el ámbito mítico que interpretó por vez primera en las Leyendas de Guatemala. En la nueva novela, más que en sus textos anteriores, incluyendo las leyendas de El espejo de Lida Sal ${ }^{29}$, se aprecia la adhesión del escritor a una especie de surrealismo indígena ante litteram, según el cual todo parece estar como en suspenso entre la realidad y el sueño. Yo no dudaría en acercar el mundo de la Mulata, por su descomunal arquitectura y fuerza representativa, mutatis mutandis, al de Michelangelo en la Capilla Sixtina. Sólo un genio podía llegar a semejantes alturas, un genio que se forja él mismo sus enseres expresivos, el vehículu lingüístico, descomponiendo y recreando el castellano, en una línea original que le acerca a su gran antecesor hispano, Quevedo, autor cuyo mensaje lo seguirá nutriendo hasta los momentos finales y más críticos de su existen$\mathrm{cia}^{30}$.

En 1965, cuando iba a tratar de Mulata de tal, respondiendo con su acostumbrada gentileza a mi pedido, Asturias me enviaba algunas explicaciones referentes a esta novela. Es posible interpretar así, desde adentro, desde su autor, el texto. Subraya el escritor que la presencia en la novela del elemento popular y la incidencia del mito tienen la función de rescatar en el tiempo la memoria de un capital de genuina cultura: ceremonias, fiestas religiosas, costumbres y creencias, leyendas y supersticiones, todo «lo que constituye el mundo popular, un mundo que el escritor -declara hablando en tercera persona- ve paulatinamente desaparecer frente a la civilización mecanizada invadente» ${ }^{31}$.

Asturias se asigna, así, la función de conservador e intérprete de un universo de valores positivos, del cual la novela es repertorio e ilustración. En realidad, Mulata de tal es pretexto para afirmar la adhesión del narrador al mundo guatemalteco, adhesión que el exilio y el paso de los años acentúan. La novela es, por consiguiente, una reinterpretación del mundo guatemalteco a través de una evidente exaltación creativa, y tiende a afirmar la moralidad del mundo indígena, arraigado en sus mitos, frente a una clase dominante que desconoce los valores profundos, perdida como va tras el poder y la riqueza.

Representación simbólica, la aventura de Celestino Yumí, el cual vende su mujer, a Tazol, demonio del maíz, para obtener riqueza y así, satisfacción estéril, imponerse a su compadre Timoteo Teo Timoteo. De esta manera Mulata de tal viene a ser parábola cautivante. Explica Astrurias que la conseja popular, antiquísima, de la venta al diablo de su propia mujer para obtener riquezas agrícolas o áureas, y la leyenda de la «mujer-luna», o «Mulata de tal», o "Fulana de tal», que nunca se le concede al hombre sino de espaldas, porque de otra manera engendraría monstruos. Queda en la superficie la intención de denunciar al infeliz Celestino, Fausto degradado, la abyección de quien todo lo sacrifica por el

\section{7}

Jimena Sáenz, Genio y Figura de Miguel Ángel Asturias, Buenos Aires, EUDEBA, 1974, pág. 216.

\section{8}

M. A. Asturias, El Alhajadito, Buenos Aires, Editorial Goyanarte, 1961, pág. 13.

\section{9}

Las leyendas de El espejo de Lida Sal, se publicaron en México, Siglo XXI, 1967.

\section{0}

CFr. mis ensayos: «Miguel Ángel Asturias y Quevedo (documentos inéditos), en AA. VV., Homenaje a Francisco Sánchez Castañer de la revista Anales de Literatura Hispanoamericana, VI, 7, 1980; «Tres momentos quevedescos en la obra de Miguel Ángel Asturias", en AA. VV., Homenaje a Luis Alberto Sánchez, Madrid, Insula, 1980

31

M. A. Asturias, "Algunos apuntes sobre Mulata de tal», texto publicado por mí antes en Studi di Lefteratura Ispano-americana, 5, 1974; ahora puede consultarse en "Apéndice» a mi libro Mundo mágico y mundo real. La narrativa de Miguel Ángel Asturias, op. cit. Cfr. la cita ibidem, pág. 225.
Recuperación del mundo precolombino y colonial en la narrativa de Miguel Ángel Asturias GIUSEPPE BELLINI 
M.A. Asturias, Mulata de tal, Buenos Aires, Editorial Losada, 1974 (4ª ed), pág. 46.

33

Ibidem, pág. 93.

34

Motolinía, Carta al Emperador. Refutación a Las Casas sobre la Colonización española, Introducción y notas de J. Bravo Ugarte, S. J., México, Editorial Jus, 1949, pág. 52.

\section{5}

M. A. Asturias, Mulata de tal, op. cit., pág. 172.

36

M. A. Asturias, "Algunos apuntes sobre Mulata de tab), op. cit., pág. 227.
Recuperación del mundo precolombino y colonial en la narrativa de Miguel Ángel Asturias GIUSEPPE BELLINI dinero, y más si por obtenerlo acaba vendiendo a los seres más queridos, su mujer, a la que luego seguirá añorando por el resto de su vida, hasta finalmente rescatarla, con la consecuencia de volver a su anterior pobreza.

Con el mito corriente, Asturias implica la lección de la vida del Cristo a quien el diablo, en su tercera tentación, lleva a la cumbre de un monte para mostrarle todo lo que le iba a dar si le adoraba. De la misma manera Tazol lleva a Celestino, subido en un árbol de tamarindo que crece sin cesar, a ver las cuantiosas riquezas agrícolas que se dispone a darle a cambio de su mujer. Si el ser divino no cede y echa al maligno, el humano acepta y se pierde.

Ya entrado en el ámbito de lo demoníaco por su pacto con Tazol y rico, Celestino va al encuentro de su desgracia cuando da con la terrible Mulata, mujer carnal, avasalladora: una fiera, un «mar de olas con uñas», y en ocasiones sedienta de sangre humana, si asalta al pobre amante, le hace manar sangre, «que paladeaba y se tragaba, mientras le arañaba, táctil, plural, con los ojos blancos, sin pupilas, los senos llorosos de sudor» ${ }^{32}$. Al final el pobre, ayudado por su diminuta esposa que ha rescatado, encierra a la fiera en una cueva y los dos, nuevamente pobres, venganza de Tazol, regresan a Quiavicús, donde nadie ya los reconoce. Su experiencia no ha sido inútil: han aprendido que «la buena vida es la vida y nada más, porque la vida en sí es lo mejor que tenemos» ${ }^{33}$.

Celestino Yumí volverá a su trabajo de leñatero, pero por poco tiempo, puesto que, debido a su trato con Tazol, «queda tocado de lo inefable, o brujería, de una especie de luz o resplandor misterioso". La pareja va a emprender, así, como en un tiempo de purgación-iniciación, nuevas aventuras, primero haciendo bailar un oso en las ferias, favorecida por los «jabalíes», que les enseñan a ocultarse tras la repetición de sílabas despistantes antes y después de su nombre, a fin de evitar que los identifiquen las fuerzas que los persiguen, actitud propia del indio frente a los extraños, juego lingüístico en el que transparentemente el escritor se divierte.

La nueva aventura concluye con las «vueltas del diablo» y es donde el diablo, fingiéndose un campesino, trata de robarle a Celestino su esposa pegándosela a la espalda, pero éste se la arrebata y en el esfuerzo por des- prenderla, tirándola de los pies, la vuelve a sus dimensiones naturales, cuando Tazol la había reducido a figurita de nacimiento.

Reafirmada de esta manera la moralidad del mundo indígena y al mismo tiempo el valor de la magia, se abre una etapa nueva de aventuras para la pareja; el ámbito donde se desarrolla será Tierrapaulita, «tenebroso reino de la magia negra». Es aquí donde nuevamente Asturias contrapone su mundo de raíz indígena al de raíz occidental, para confirmar que con la conquista y la introducción de la religión cristiana han entrado en América el concepto del pecado y el demonio. No era el continente americano la tierra donde, según denunciaban Motolinía y los evangelizadores seráficos, el demonio «era muy servido» ${ }^{34}$, sino que el maligno lo habían llevado los mismos occidentales.

Cuando Celestino y su esposa, ya «poderosa Giroma» por haber concebido, preñada de Tazol, a Tazolito, llegan a Tierrapaulita, se encuentran con un mundo torcido: casas, calles, hombres y animales, la iglesia misma y el cura; es el mundo del pecado, del que ya, después de dura lucha, se han alejado los demonios terrígenas, vencidos por el demonio cristiano, no sin haber condenado Cashtoc -la más alta divinidad infernal del panteón derrotado- al hombre, por haber pretendido vivir «ajeno a los millones de destinos que se tejen $y$ destejen alrededdor suyo» ${ }^{35}$.

Trastornada la estructura armónica del mundo indígena con la conquista y la nueva religión, reina el caos y al final el mundo del pecado acaba por ser destruido: Tierrapaulita es «quemada con lava blanca -explica Asturias-, reminiscencia, en la creencia popular, del castigo celeste a las ciudades pecaminosas» ${ }^{36}$. Nuevamente el escritor realiza así un mestizaje de culturas, en este caso de textos sagrados: el Popol-Vub que relata la destrucción de los muñecos u hombres de madera, y la Biblia, donde se cuenta la destrucción de las ciudades pecadoras de Sodoma y Gomorra.

Después del estallido y la lluvia de fuego, un enorme silencio lo ocupa todo:

El silencio también callaba entre los cielos y la tierra, mientras iba pintando el día cubierto de plumas de fuego inmensas, sobre las que en estrías aún más luminosas corrían regueros de plumitas de colores que se amontonaban empujadas por quién sabe qué vien- 
tos, hacia sitios en que estuvo Tierrapaulita, y está, sólo que enterrada ${ }^{37}$.

Otros puntos de contacto realiza Asturias en Mulata de tal con el mundo precolombino. Es el caso del duro combate entre el cura de Tierrapaulita, «araña ensotanada», y el puercoespín, o demonio, que para el escritor representa

la constante desgarradura de la conciencia del hombre americano, del mestizo, entre las dos creencias, las dos religiones en que se informan, la tragedia de todo lo que le es adverso, representado aquí por la espina del puercoespín, y la sotana, creencia llegada de fuera ${ }^{38}$.

«Confusión de diabolismos»-añade-donde se mezclan macabras ceremonias de la Edad Media y del mundo indígena, «desde los asaetamientos a las víctimas, hasta los sacrificios en que se arrancaban los corazones para alimentar al sol ${ }^{39}$.

La victoria de Satán es su condena para la Mulata, ahora en el cuerpo del sacristán, por no haber sabido luchar como debía contra el demonio cristiano encarnado en Yumí. La lucha entre el cura-araña y el puercoespín termina con la misa de muerto y esponsales, en la que la Mulata intenta hacer suyo a Yumí, pero su legítima mujer le roba el sexo por mano de una segundona y frustra su intención. Aquí nuevamente nos socorre Asturias interpretando el pasaje:

La Mulata no sólo se queda sin sexo, sino que es sometida al castigo de otras mutilaciones por parte de los brujos. Es la viuda amarilla, o Viuda del Maíz, y la vinda amarilla sólo puede ser aquella a quien se le muere el marido, el esposo, el hombre amarillo, es decir el maíz. A la que se le ha muerto el maíz, a la viuda amarilla, se le ha muerto todo, porque decir maíz es decir riqueza, bienestar, comida, lujo, sartales de piedras preciosas, trajes, fiestas, hijos, alegría, felicidad, gusto por las cosas de la tierra ${ }^{40}$.

Un nuevo punto de contacto con el mundo precolombino lo demuestra el uso simbólico del tabaco. El escritor lo explica de esta manera:

En lo que toca al tabaco, planta que cuando Satán era Arcángel descubrió en el Paraíso Terrenal -y fue con- denada a la destrucción, a salir del Paraíso, porque era la única planta inteligente, con inteligencia-, el Ángel de la Luz la lanza hacia un mundo verde en formación: América. Y allí [Satán] la encuentra, cultivada por los indios. Para éstos es una planta sagrada, un «veneno sagrado", y que sólo debe ser conocido de los sacerdotes y adivinos. Satán no acepta que aquella planta quede circunscrita a un grupo, pues debe propagarse entre los hombres. Dos concepciones: la indígena, el tabaco como planta sagrada, «veneno sagrado», "veneno mantenedor», y la de Satán (el conquistador, el blanco), el tabaco como planta de placer, sin preocuparse de su terrible toxicidad ${ }^{41}$.

La mezcla de elementos no impide que el indígena sea para Asturias siempre el mundo positivo, contaminado negativamente por el europeo. Lo mismo ocurre con el tema de la procreación, que el demonio cristiano, a quien se le opone el cura, empujando al «engendro», propaganda como acto carnal y pecaminoso, para condenar al hombre, mientras en la concepción indígena representaba el elemento que armoniza al universo.

8. Con la nueva novela, Maladrón, Asturias vuelve cronológicamente atrás, puesto que en esta obra, que subtitula Elegía de los Andes Verdes, trata de la derrota del pueblo Mama frente a los conquistadores, a raíz de la cual un grupo de aventureros irá merodeando por el mundo centroamericano, en busca infructuosa de la conjunción de los Océanos, problena dominante durante todo el período de la Conquista. Una serie de historias dentro de la historia representa la múltiple aventura que lleva al primer éxito mestizo: el nacimiento del hijo de la india Titil-Ic y del conquistador español.

La primera parte de Maladrón presenta la llegada de los conquistadores a tierra mesoamericana, el papel del mundo indígena en su drama, favorecido por su especial mentalidad frente a la europea: creencia en el poder de la magia, que resulta vencida por la técnica europea de la guerra. El jefe Mam tiene perfecta conciencia de que todo ha cambiado y que ellos están destinados a la derrota, pero nadie comprende su drama y lo echarán del poder condenándolo al destierro en un país desolado, el del «Lacandón y el mono», mundo sin tiempo.

La historia se presenta sencilla, pero nuevamente Asturias ahonda en el examen del
37

M. A. Asturias, Mulata de tal, op. cit., págs. 298-299.

38

M. A. Asturias, "Algunos apuntes sobre Mulata de tal», cit., pág. 226.

39

Ibidem.

40

Ibidem.

41

Ibidem, pág. 227.
Recuperación del mundo precolombino y colonial en la narrativa de Miguel Ángel Asturias GIUSEPPE BELLINI 
42

El poema lo publica en Buenos Aires, Editorial Losada, 1965.

\section{3}

Amos Segala, «Introduzione» a M. A. Asturias, Clarivigilia Primaveral, Milano, AccademiaSansoni, 1971, pág. 22.

\section{4}

M. A. Asturias, El espejo de Lida Sal, México, Siglo XXI, 1967, pág. 3.

\section{5}

Véase sobre la novela el importante estudio de Dorita Nouhaud, «Maladron» de Miguel Ángel Asturias, Paris, L'Harmattan, 1993.

\begin{abstract}
46
Ver la lograda interpretación de Dorita Nouhaud en su «Introducción» a M. A. Asturias, Tres de cuatro soles, ed. crítica, Paris, Editions Klincksiek, 1977 y su libro sucesivo, La brulure de cinq soleils. Biographie raisonnée de M. A. Asturias, Limoges, Presses de l'Université de Limoges et du Limousin, 1991.
\end{abstract}

\section{7}

A. Segala, «Nota al texto de Asturias», en Romanica Vulgaria, 4-5, 1982, pág. 52. Tres de cuatro soles fue publicado antes en francés: Trois des quatre Soleils, traduction de Claude Couffon, Genève, Skira, 1971, y en su original castellano por D.Nouhaud, ed. cit.

48

M. A. Asturias, El Árbol de la Cruz, edición facsimilar de $A$. Janquart y A. Segala, Madrid, ALLCA XX, 1993.

\section{9}

M. A. Asturias, Viernes de dolores, Buenos Aires, Editorial Losada, 1972.

\section{0}

Cfr. M. A. Asturias, L'homme qui avait tout tout tout, traduit par J. Garavito, images de Jacqueline Duhème, Paris, Éditions G. P., 1973. El texto castellano se publica sólo en 1982, en Románica Vulgaria, 4-5, 1982. destino de su gente. La dimensión de la tragedia que ha hundido todo un universo asume en su obra proporciones apocalípticas y el escritor, a través de una prosa rica en humores y colores, destaca la dimensión profunda de la catástrofe que hundió toda una civilización.

La lucha del héroe Chinabul Gemá, que acaba derrotado y muere, envía al lector a la que sostuvo el mítico Tecún-Umán contra Alvarado. Asturias celebra al héroe con participación, acudiendo estilísticamente, en el pasaje, a la iteración y al paralelismo, según la antigua poesía épica indígena y logra dar vida a un clima de alta celebración. A pesar de que la prosa del guatemalteco siempre es sumamente poética, en estas páginas la característica se acentúa. Es el momento, por otra parte, en que Asturias vuelve a componer poemas, ejercicio que parecía haber olvidado: en 1964, estando exilado en Génova, compone el largo poema Clarivigilia Primaveral ${ }^{42}$, una de sus mayores creaciones, donde, tratatando el origen de los artistas, los únicos que dan sentido al mundo, da vida a un mítico reino de esplendor y sacralidad mágica.

Amos Segala define el poema «una cosmogonía che ripete a suo modo e con una impostazione assolutamente inconfondibile e personale la storia degli dei e degli uomini, delle loro opere e delle loro sofferenze», y destaca su íntima concordancia con los libros sagrados de los orígenes maya, pero con «uno smalto lessicale e una ellitticità forse superiorì ${ }^{43}$.

Nunca hay que olvidar que el mundo precolombino es, para Asturias, un añorado y esplendoroso reino perdido. Una vez más lo representa en El espejo de Lida Sal como «región del alma» una perspectiva de «paisajes dormidos», iluminados por una luz «de encantamiento y esplendor», "memoria del temblor de la luz», país verde, formado por «valles, colinas, selvas, volcanes, lagos verdes, bajo el cielo azul sin una mancha» ${ }^{44}$.

El contacto con el Popol-Vub es transparente: estamos nuevamente ante el Paraíso terrenal, sobre el que reina un tiempo eterno; paraíso que en Maladrón acentúa aún más sus características positivas: «mundo de golosina», poblado de gente tranquila, venados y pavos azules; mundo maravilloso al que los «seres de injuria» ponen fin ${ }^{45}$.

En este choque violento entre mundos diferentes, acaso Asturias siga la concepción cíclica indígena, según la cual cada nueva edad empezaba con la extinción violenta de la que la había precedido. De todos modos, por más que el mestizo Asturias haya aceptado, y hasta sublimado, el mestizaje, el mundo americano queda para él, en la actualidad, desposeído de la magia y él mismo un ser que, habiendo perdido el Paraíso, no hace más que perseguirlo y evocarlo.

Lo hará sustancialmente también en Tres de cuatro soles, texto narrativo-filosófico, de impervia interpretación ${ }^{46}$, más que nunca cerca del Popol-Vuh, de honda filosofía, o, como lo interpreta Segala, "storia personale e storia del mondo, summa biografica e cosmica ${ }^{47}$. Una historia que enriquece el fragmento de $E l$ Árbol de la Cruz, publicado póstumamente en $1993^{48}$, siendo la novela Viernes de dolores, de $1972^{49}$, y L'bomme qui avait tout tout tout, de $1973^{50}$, los últimos textos publicados en vida por el escritor, este último también significativo dentro del clima vitalista de una plural mitología, sobre un fondo de una naturaleza mágica, con la punición-salvación final del protagonista, trasnformado en árbol de aguacate.

Entraría por fin Asturias en el «reino del esplendor» y se aquietaría su búsqueda del mundo que con tanto ahinco y controlada nostalgia se había empeñado en interpretar. 